\title{
Climatic Forecasting of Net Infiltration at Yucca Mountain, Using Analogue Meteorological Data
}

\section{Boris Faybishenko (LBNL)}

Net infiltration is a key hydrologic parameter that controls the rate of deep percolation through the unsaturated zone, the groundwater recharge, radionuclide transport, and seepage into the underground tunnels. Because net infiltration is largely affected by climatic conditions, future changes in climatic conditions will potentially alter net infiltration. The objectives of this presentation are to: (1) Present a conceptual model and a semi-empirical approach for regional, climatic forecasting of net infiltration, based on the precipitation and temperature data from analogue meteorological stations, and (2) Demonstrate the results of forecasting net infiltration for future climates-interglacial, monsoon and glacial — over the Yucca Mountain region for the period of 500,000 years. Calculations of the net infiltration were performed using a modified Budyko's waterbalance model, for which potential evapotranspiration was evaluated from the temperature-based Thornthwaite formula. (Both Budyko's and Thornthwaite's formulae have been used broadly in hydrological studies.) The results of calculations were used for ranking net infiltration, along with the aridity and precipitation-effectiveness (P-E) indexes, for future climatic scenarios. Using this approach, we determined a general trend of increasing net infiltration from the present-day (interglacial) climate to monsoon, intermediate (glacial transition), and then to the glacial climate. Ranking of the aridity and $\mathrm{P}-\mathrm{E}$ indexes is practically the same as that of net infiltration. The validation of the computed net infiltration rates yielded a good match with other field and modeling study results of groundwater recharge and net infiltration evaluation. 